\title{
"REVOLTADOS ONLINE" E AS MANIFESTAÇÕES CONTRA O GOVERNO FEDERAL BRASILEIRO: NOTAS INICIAIS DE UMA PESQUISA
}

\author{
Matheus Henrique Marques Sussai (UEL - História) \\ Orientadora: Profa. Dra. Márcia Elisa Teté Ramos
}

\begin{abstract}
RESUMO
A presente comunicação visa apresentar as considerações iniciais de uma pesquisa de História no ciberespaço. Pretendemos analisar as manifestações contra o governo federal durante os meses de julho a dezembro de 2014. Para isso, utilizaremos como fonte documental uma comunidade virtual da rede social online Facebook, chamada "Revoltados ON LINE". Metodologicamente, analisaremos as publicações da página junto com o seu grau de aceitação e compartilhamento das ideias, e os comentários dos seguidores e daqueles que são contra as ideias veiculadas pela comunidade. Assim, pretendemos apresentar as temáticas mais recorrentes, buscando investigar os argumentos para as manifestações contra o governo, os embasamentos políticos da comunidade, quantificar o número de compartilhamentos, comentários e "curtidas" das publicações, tomando o Facebook como uma fonte para a pesquisa histórica do tempo presente. Como perspectiva teórica para pensarmos o ciberespaço, utilizaremos Pierre Lévy $(1993,1999)$ para falar do mundo virtual, e de Kozinets (2014) para entender a netnografia, entre outros. Como resultados esperados, pretendemos mostrar como a comunidade dissemina determinados modelos de argumentação sobre política, quantificando-os em tabela. Não tomaremos posições partidárias, o interesse está em investigar a política de direita no Facebook.
\end{abstract}

Palavras-chave: História do Tempo Presente; Ciberespaço; "Revoltados ON LINE”.

\section{INTRODUÇÃO}

O presente trabalho visa apresentar os primeiros passos de uma pesquisa de História que se dedica a estudar o ciberespaço enquanto fonte documental. As primeiras ideias, empecilhos, discussões, serão expostas e trabalhadas aqui para uma melhor compreensão da pesquisa, tanto dos leitores, quanto nossa, pois, o momento inicial de uma pesquisa é onde ela mais se subestima a várias revisões, novos pensamentos, novas abordagens. Isso não significa que depois de pronta, uma pesquisa não merece revisões. Pensamos justamente o contrário disso. A questão é que esse momento é propício para discutir um trabalho que está por vir, e que quer ter rigor e métodos científicos.

Colocar em discussão essa pesquisa que surge com o intuito de discutir um pouco do contexto histórico e político contemporâneo do Brasil, tratando do ambiente virtual como fonte, é relevante para pensarmos novas possibilidades, abordagens, e visões para o nosso trabalho. Por isso, discorreremos sobre as abordagens pensadas para o nosso trabalho, que visa analisar uma comunidade virtual online, encontrada na rede social online Facebook ${ }^{1}$ Essa comunidade é denominada de

\footnotetext{
${ }^{1}$ O Facebook é uma plataforma virtual, criada em 2004. É uma rede social online, onde seus usuários possuem a capacidade de compartilhar e discutir vídeos, imagens, textos, entre outros tipos de mídia. Além de possuir chat para conversas privadas, os usuários podem criar álbuns de fotos e vídeos sobre a sua vida pessoal, e utilizar inúmeros aplicativos fornecidos pelo Facebook. Com grandes potencialidades comunicativas, vem reunindo milhões de pessoas ao redor do mundo (COUTO JUNIOR, 2013, p. 29).
} 


\section{SEMINÁRIO DE PESQUISA EM CIÊNCIAS HUMANAS - SEPECH \\ Humanidades, Estado e desafios didático-científicos \\ Londrina, 27 a 29 de julho de 2016}

"Revoltados ON LINE" 2 , e desde a sua criação em 2010, se manifesta contra o governo federal, que desde aquele ano, continua som o mesmo representando a presidência da república, o Partido dos Trabalhadores (PT). É no período eleitoral de 2014 - que se inicia em julho com as propagandas eleitorais, até outubro, com os resultados do segundo turno -, e principalmente devido à reeleição da presidente Dilma Rousseff, que a comunidade ganha membros, força, difusão e repercussão na sociedade brasileira que frequenta o espaço virtual.

Por isso, pretendemos analisar os meses entre julho e dezembro do ano de 2014, abrangendo o período eleitoral, o pós-eleição, e como foi a finalização do ano e a situação política do país. É importante lembrar que esse movimento, hoje, é muito mais forte, contando com a participação de $1.648 .074^{3}$ pessoas na comunidade, ou, "curtidores", conceito utilizado pelo Facebook para designar as pessoas que seguem/participam da comunidade. A intenção, em suma, é investigar essas manifestações difundidas pela comunidade, e os comentários das publicações. Claro que seguiremos um método de escolha das fontes, mas cabe dizer que os participantes são um dos pontos principais nesse novo formato de mídia, e não só as publicações que os organizadores da página difundem.

Enfim, esperamos colaborar com essa discussão para novas abordagens de pesquisa em História, mas também para refletirmos sobre a História do Tempo Presente brasileira, aludindo ao contexto histórico, político, cultural e social que este tema aborda. A cada dia que passa mais pessoas entram em contato com o mundo virtual, e essas tem a possibilidade de se informar sobre política em comunidades como a que estudamos. É preciso parar para discutir essa fonte que se coloca para historiadores, antropólogos, cientistas políticos e sociais, e que penetram cada vez mais profundamente o cotidiano de muitos brasileiros.

\section{BREVE DISCUSSÃO TEÓRICA E APRESENTAÇÃO DO TEMA (PROBLEMA)}

As redes sociais virtuais possuem muita importância na formação de opiniões das pessoas. Opiniões que permeiam entre política, religião, lazer, modos de vida, entre tantos outros temas que estão no mundo virtual atualmente. É da emergência desses formadores de opiniões online, ou "web atores", como veremos adiante, que esse projeto se interessa em investigar as manifestações de uma comunidade virtual do Facebook contra o governo federal brasileiro (2014, de julho a dezembro).

Estudar as postagens online em uma plataforma como o Facebook é um desafio para o historiador, uma vez que são fontes relativamente recentes e pouco utilizadas, estando carregadas com as marcas do presente. Os diversos tipos de postagens, junto com os comentários dos usuários das redes sociais, criam um gigantesco acervo "aberto" e "movediço", uma vez que existe a possiblidade da alteração dos documentos, e também a exclusão ou acréscimo de comentários (RAMOS, 2012, p. 669), ou seja, "[...] a qualquer momento conteúdos podem ser adicionados, apagados ou modificados,

\footnotetext{
${ }^{2}$ Disponível em: $<$ https://www.facebook.com/revoltadosonline/?fref=ts $>$. Acessado em 13 de maio de 2016.

${ }^{3}$ Disponível em: $<$ https://www.facebook.com/revoltadosonline/likes $>$. Acessado em 13 de maio de 2016.
} 


\section{SEMINÁRIO DE PESQUISA EM CIÊNCIAS HUMANAS - SEPECH \\ Humanidades, Estado e desafios didático-científicos \\ Londrina, 27 a 29 de julho de 2016}

bem ao tom da dinamicidade que caracteriza a Web 2.0." (LUCCHESI, 2014, p. 41). Para isso, o recurso Print Screen de captura de imagens do Windows proporcionará a criação de documentos e de um acervo digital das postagens e comentários que serão analisados.

Não só o caráter "movediço" das fontes, o estudo da história do tempo presente, ou um passado pouco distante, como é o caso do nosso estudo, traz consigo a dificuldade de não saber aonde esses acontecimentos levam, de não saber os seus resultados (HOBSBAWM, 2013, p. 326). A interdisciplinaridade mais uma vez se mostra necessária para o estudo histórico, inclusive com fontes de cunho digital e online, uma vez que poucos historiadores até o momento se arriscaram a pesquisá-las. Ainda assim, vemos que os fundamentos da disciplina da história continuam os mesmos, uma vez que a história digital e as tecnologias não operam uma ruptura radical, mas sim, acrescentam novas ferramentas à oficina da história (LUCCHESI, 2014, p. 52).

$\mathrm{Na}$ considerada primeira idade das mídias, com a televisão, o cinema, as músicas, a fotografia, também chamadas de "mídias massivas", "[...] o fluxo da informação se dá na perspectiva "um-todos"' (COUTO JUNIOR, 2013, p. 39), onde existe um veículo de difusão da informação, e resta às outras pessoas o papel de receptor (isso não significa uma interpretação pacífica de cada indivíduo, que pode reelaborar ou mesmo transgredir as mensagens midiáticas). Diferente do que acontece na Web 2.0, termo criado por Tim O'Reilly em 2004, para apontar as diferenças em relação a Web 1.0, onde os aprimoramentos feitos aos websites, adicionaram novas funcionalidades que permitiram uma maior participação dos usuários da Web.

Dito isso, o que acontece nos processos comunicacionais mediados pelas mídias digitais, nesse caso, pelo Facebook, uma mídia de cunho "pós-massivo", é a veiculação da informação com uma comunicação "todos-todos" (COUTO JUNIOR, 2013, p. 2239). É um espaço virtual online onde todos ajudam a preencher, uma rede que é alimentada a todo o momento, e por todos os participantes, não havendo apenas um difusor, mas sim todos difusores e receptores, compartilhando e ressignificando vários tipos de mídia. É isso que diz o estudioso de "cibercultura" André Lemos (2010), ao mostrar que as mídias pós-massivas proporcionam a "liberação da palavra", onde "[...] permitem a qualquer pessoa, e não apenas empresas de comunicação, consumir, produzir, e distribuir informação sob qualquer formato em tempo real e para qualquer lugar do mundo." (p. 25).

É a partir dessa transformação de Web 1.0 para $W e b 2.0$, e a mudança do simples receptor, ou telespectador, para o navegador atuante, criador e difusor de ideias no mundo da cibercultura, é que os estudiosos de novas tecnologias Francis Pisani e Dominique Piotet (2010, p. 119), vão escolher o termo "web ator" para designar usuários da Web 2.0, a internet que conhecemos hoje. "Os internautas utilizavam a internet. Os web atores a trabalham com o conteúdo que geram e com a capacidade de organizá-lo." (PISANI; PIOTET, 2010, p. 120).

É com esse referencial que trataremos a nossa fonte de estudo: a comunidade virtual do Facebook "Revoltados ON LINE". Tomaremos como web atores tanto a página (criada por uma pessoa), quanto os seus participantes (os que seguem a página, compartilham de suas ideias), não deixando de lado os comentaristas das postagens, que discutem sobre os assuntos veiculados pela comunidade virtual. Esses que, nem sempre 


\section{SEMINÁRIO DE PESQUISA EM CIÊNCIAS HUMANAS - SEPECH \\ Humanidades, Estado e desafios didático-científicos \\ Londrina, 27 a 29 de julho de 2016}

estão atuando para concordar com as ideias da página, o que gerou vários debates entre esses web atores, e que serão tidos por nós como fontes para o estudo da História.

No Facebook, as "comunidades virtuais", termo cunhado pelo trabalho pioneiro de Howard Rheingold, que "[...] sinalizou o poder de mobilização dos coletivos digitais conectados [...]" (PASSARELLI, 2010, p. 66), se caracterizam por reunir participantes que possuam interesses e afinidades em comum. Vemos aqui uma transformação nas formas de se comunicar, onde a afinidade ao outro media à procura de relações online. $\mathrm{O}$ "ciberespaço torna-se uma forma de contatar pessoas não mais em função de seu nome ou de sua posição geográfica, mas a partir de seus centros de interesse" (LÉVY, 1999, p. 100 apud COUTO JUNIOR, 2013). Esse sentimento de pertencimento, devido aos interesses em comum daqueles que fazem parte da comunidade virtual, é muito relevante para nosso estudo. A identidade desses web atores resulta de "[...] um sentimento de diferença diante de outras comunidades. Pertencer significa simultaneamente ser incluído em uma comunidade e estar separado e diferenciado de outra." (AIRES; AZEVEDO, 2010, p. 39).

Essa relação dos usuários de pertencimento a um grupo, devido as suas ideias, afinidades e interesses em comum, são características das "comunidades virtuais", o que as fortalecem cada vez mais como formadoras de opinião. Como é o caso da "Revoltados ON LINE", comunidade virtual fundada no dia 01 de agosto de 2010, que se objetiva a criticar e se manifestar contra o governo federal do Brasil. É importante lembrar que no ano de 2010, aconteceram as eleições presidenciais, que resultaram na continuação do Partido dos Trabalhadores com um novo representante na presidência do país. Desde o seu início, a comunidade virtual usa de suas publicações para demonstrar a sua oposição ao Partido dos Trabalhadores e as suas ações enquanto partido que atua na presidência do país.

A comunidade virtual apresentava 1.141 .707 "curtidas" no dia 17 de novembro de 2015, número notadamente diferente do que vimos na introdução deste texto (1.648.074). Vemos como que em menos de um ano (novembro de 2015 a maio de 2016), o número de pessoas, que já era alto no primeiro momento marcado, subiu significantemente. São mais de 500 mil pessoas que se inscreveram nesse tempo. Essas "curtidas" não param de crescer, demonstrando uma maior aceitação das pessoas para com as ideias veiculadas pela página. É por isso que pretendemos investigar as publicações dessa comunidade e as discussões realizadas pelos web atores, buscando os argumentos centrais da página e as suas principais críticas ao governo no ano de 2014 (de julho a dezembro). Ano esse em que ocorreram novas eleições presidenciais, onde novamente resultou na continuidade do Partido dos Trabalhadores na presidência do governo.

Os usuários da plataforma Facebook possuem as mais diversas idades. Contudo, a maior participação dos jovens nessa plataforma é notável, devido ao contato que tiveram mais cedo com as novas tecnologias, desenvolvendo sua "literacia digital": habilidades em usar os recursos disponíveis na rede mundial de computadores e nos demais ambientes virtuais." (RAMOS, 2012, p. 673). Por isso, torna-se necessário compreender os jovens como "produtores de sentidos e autores que tecem coletivamente saberes, deixando marcas e manifestações culturais nas redes sociais digitais [...]" (COUTO JUNIOR, 2013, p. 37).

As relações no ciberespaço constituem novas maneiras de se socializar, de construir e difundir as mais diversificadas ideias e informações. As redes sociais online, 


\section{SEMINÁRIO DE PESQUISA EM CIÊNCIAS HUMANAS - SEPECH \\ Humanidades, Estado e desafios didático-científicos \\ Londrina, 27 a 29 de julho de 2016}

presentes na $W e b 2.0$, enquadram em seu modo divulgação da informação, os outros tipos de mídia (textos, vídeos, áudios, imagens, entre outros). É a partir dessas novas formas de se comunicar, de formar opinião, difundi-la, que assuntos da vida pública e privada são constantemente discutidos no ambiente do ciberespaço. Assuntos que, como é o caso da nossa fonte, tocam no âmbito da esfera política e cultural brasileira.

\section{JUSTIFICANDO O NOSSO TRABALHO}

A opção pelo tema e pelo objeto de pesquisa a ser trabalhado ocorre devido à constatação de que na atualidade há grande participação das redes sociais online no cotidiano. Grande parte das pessoas utiliza algum tipo de rede social online, onde interagem das mais diversas maneiras com as ferramentas que as novas mídias oferecem. Sendo, por exemplo, o Facebook, a Web 2.0 é uma mídia original, mas que se utiliza dos aparatos das outras mídias (visual, áudio, texto, etc.). As pessoas leem, assistem, ouvem, e o mais interessante para nós: participam ativamente interagindo e colaborando para a existência dessas redes sociais.

É nesse campo do ciberespaço que se criam novos meios de se relacionar, novas sensibilidades e racionalidades. No entanto, o ciberespaço, embora traga mudanças em nossa formação cultural, trazendo a marca do novo, da inovação e modernidade, não garante que as opiniões, as crenças, as noções, tenham também se transformado em algo "mais elaborado" ou fundamentado. O objeto, desta forma, se insere neste jogo complexo de mudanças e permanências, de inovação e de reelaboração de perspectivas do passado.

Assim, a plataforma Facebook também pode ser vista como um espaço de pesquisa para o historiador, pois, é neste ciberespaço que hoje grande parte dos brasileiros expõem as suas opiniões políticas, religiosas, seus desejos, suas fotografias, suas experiências vividas, entre outros. A $W e b 2.0$ se tornou um imenso acervo online à espera de novas pesquisas que se fazem necessárias para a compreensão de certos aspectos do século XXI. Os modos de se relacionar se modificam a todo o momento, e o ciberespaço possibilitou a interação das pessoas na mídia, onde essas possuem o principal papel, não sendo apenas receptoras, mas participantes.

Sendo o Facebook umas das redes sociais online mais conhecidas mundialmente, é relevante que pesquisadores se interessem pelo acervo que essa plataforma oferece para investigação. Sendo a História uma ciência que também tem por interesse o presente, é relevante que se atente ao local onde grande parte das relações sociais contemporâneas está acontecendo: o ciberespaço. Este se tornou um local de fácil acesso, e com o passar do tempo, tende a aumentar o número de participantes, já que é cada vez mais comum as novas gerações se adaptarem facilmente a esse tipo de mídia, pois tem mais tempo para construir a sua "literacia digital" e se adaptar ao universo cultural contemporâneo.

$\mathrm{Na}$ atual conjuntura política brasileira, os debates sobre a mesma interessam muitas pessoas, que acabam utilizando da Web 2.0 para veicular as suas opiniões, debater, se informar, e participar dessas discussões políticas. A comunidade virtual "Revoltados ON LINE" é uma de muitas que se contrapõem ao governo federal brasileiro, mas sendo possível encontrar no Facebook defesas e críticas de todos os lados da política, religião, times de futebol, práticas culturais como um todo. Sendo as 


\section{SEMINÁRIO DE PESQUISA EM CIÊNCIAS HUMANAS - SEPECH \\ Humanidades, Estado e desafios didático-científicos \\ Londrina, 27 a 29 de julho de 2016}

manifestações contra o governo federal o assunto que mais nos interessa aqui, achamos relevante investigar os debates que giram em torno das publicações veiculadas pela comunidade, atentando para as pessoas que concordam, discordam, e quais são os seus argumentos para tal feito.

Ou seja, é a participação dos usuários nas discussões da comunidade virtual que é relevante para compreender o contexto histórico e político brasileiro. O ciberespaço se mostra aqui como uma fonte para tal tema, aonde o interesse por política vem aumentando, e principalmente no nosso caso, no contexto brasileiro, interessa muitos cidadãos que participam dessas redes sociais se informando, criando opiniões, discutindo, argumentando contra ou a favor de determinado ato de algum político, entre outros.

No nosso universo cultural, a internet e as redes sociais integram as nossas vidas. Para se estudar a história do tempo presente, a Web 2.0 se tornou um acervo riquíssimo de fontes que precisam ser pesquisadas. É no ciberespaço que hoje se tecem os novos meios de relações sociais, práticas culturais, discursos religiosos e antirreligiosos, discursos políticos, experiências vividas, entre outros. Na necessidade de se estudar as fontes do tempo presente, interessados pela atual conjuntura política brasileira, as novas mídias e novas tecnologias nos chamaram a atenção para a pesquisa histórica.

\section{O INÍCIO DE UMA METODOLOGIA: PENSANDO EM MÉTODOS}

Quanto à perspectiva metodológica, como já sugerida, utilizaremos uma comunidade virtual denominada "Revoltados ON LINE", criada em 01 de agosto de 2010, como fonte documental para investigar as manifestações contra o governo federal brasileiro. A comunidade faz parte da plataforma Facebook, uma rede social online criada em 2004, e que atualmente possui cerca de 1,5 bilhões de usuários.

Para iniciar a pesquisa, foi necessária a delimitação de um período temporal referente às postagens da comunidade online. $\mathrm{O}$ período escolhido foi de julho a dezembro do ano de 2014, devido à conjuntura política brasileira do momento, onde estavam ocorrendo as propagandas eleitorais para as eleições à presidência para o mandato de 2015 a 2018. É também o momento onde o número de participantes da comunidade virtual aumenta fortemente, mostrando um interesse de vários sujeitos em se informar e discutir sobre política perto das datas de votação eleitoral.

Para pensar a pesquisa no campo digital, ou melhor, no ciberespaço, Pierre Lévy (1993) nos mostra como o hipertexto, o que ele denomina de "[...] conjunto de nós ligados por conexões [...]", onde esses nós podem ser "[...] palavras, páginas, imagens, gráficos ou partes de gráficos, sequências sonoras [...]" (p. 33) entre outros, se utiliza do empréstimo de várias outras mídias, mas se constitui como "[...] uma rede original de interfaces" (LÉVY, 1993, p. 37). Para o autor, é um tipo novo de mídia que dialoga com as outras mais tradicionais, se utilizando delas para criar um novo tipo de mídia original, dinâmica, e mais veloz.

Com a participação dos usuários nas discussões da comunidade virtual "Revoltados ON LINE", é importante pensar em um tipo de fonte "móvel", já que existe a possibilidade de se alterar os documentos, como nos mostra Márcia Elisa Teté Ramos (2012, p. 669), e Anita Lucchesi (2014, p. 41), ao dizer que os conteúdos veiculados virtualmente podem ser apagados ou modificados a qualquer momento, uma 


\section{SEMINÁRIO DE PESQUISA EM CIÊNCIAS HUMANAS - SEPECH \\ Humanidades, Estado e desafios didático-científicos \\ Londrina, 27 a 29 de julho de 2016}

característica da Web 2.0. Devido ao caráter movediço desse gigantesco acervo encontrado no ciberespaço, a metodologia pertinente tem por objetivo criar um acervo de imagens das publicações e dos comentários a serem analisados. A partir do recurso de captura de tela (imagem) do Windows, o Print Screen, será feita essa coleta para análise dos documentos.

Devido ao alto número de comentários nas publicações, onde alguns passam de 3000, optamos metodologicamente pela captura de informações para se trabalhar com a amostragem das ideias, ou seja, serão levados em conta comentários mais significativos e que demonstram certa regularidade com as ideias disseminadas pela página. Como são muitos comentários, e o objetivo da pesquisa é investigar as temáticas regulares e as discussões mais enfatizadas pelos comentaristas sobre a atual conjuntura política brasileira, a opção metodológica da amostragem se mostrou mais pertinente ao nosso caso.

Diferente da metodologia utilizada por Dilton Ribeiro do Couto Junior (2013), que ao realizar a sua pesquisa no Facebook interfere com questões para os participantes da rede social online, nós não iremos interferir com comentários nas publicações da comunidade virtual "Revoltados ON LINE". Couto Junior (2013) também discute alguns teóricos de "etnografia virtual", termo mais comum, ou também "Netnografia" (KOZINETS, 2014), onde nós optamos por analisar a fonte tal como está, já que nosso objetivo se difere do de Couto Júnior, mas as suas discussões metodológicas acerca de cibercultura e alteridade no Facebook nos interessam muito.

A partir das publicações da comunidade virtual, mais os comentários, capturaremos as publicações mais lidas (compartilhadas, comentadas, curtidas) e os comentários mais significantes, como já foi dito, para a análise que buscará compreender os discursos políticos das postagens da página, onde esses números serão quantificados em gráficos e tabelas de acordo com os temas, as curtidas, os compartilhamentos, as ideias mais frequentes. Ou seja, a investigação da regularidade das temáticas na página é de extremo interesse, para podermos compreender suas opiniões e embasamentos políticos, que estão de acordo com os seguidores da comunidade (aproximadamente um milhão de "curtidas").

As regularidades enunciativas serão consideradas não apenas quantitativamente, mas segundo um discurso-síntese. A técnica do discurso-síntese procura blocar opiniões. Ou seja, no discurso-síntese se reúnem "conteúdos e argumentos que conformam opiniões semelhantes" (LEFEVRE; LEFEVRE, 2012, p. 17). Assim, se remete às respostas semelhantes como se fosse um depoimento único (LEFEVRE; LEFEVRE, 2012, p. 19). Esta metodologia denominada Discurso do Sujeito Coletivo (DSC), produzida na Universidade de São Paulo desde 1990, serve ao propósito de reunir depoimentos verbais e não-verbais em discursos-sínteses, entendendo que em qualquer sociedade os sujeitos compartilham e também divergem em ideias, noções, opiniões e representações, e por isso mesmo, estas podem ser percebidas conforme "padrões", fazendo o pensamento coletivo "falar diretamente" (LEFEVRE; LEFEVRE, 2012 , p. 24). O discurso-síntese não deixa de ser uma forma de categorização, uma forma de reconhecer, diferenciar e classificar aproximadamente as representações sociais.

A investigação dos argumentos centrais, dos interesses que a comunidade tem com as postagens, os seus objetivos, as suas organizações de eventos (passeatas, manifestações de rua), as propagandas políticas veiculadas pela comunidade, todos 


\section{SEMINÁRIO DE PESQUISA EM CIÊNCIAS HUMANAS - SEPECH \\ Humanidades, Estado e desafios didático-científicos \\ Londrina, 27 a 29 de julho de 2016}

esses dados serão analisados para uma melhor compreensão sobre as opiniões que estão sendo disseminadas contra (ou a favor, via comentários) do governo federal. A metodologia pretende não ignorar os comentários dos participantes justamente por ser uma das principais características da Web 2.0, o seu caráter de mídia "pós-massiva" (COUTO JUNIOR, 2013, p. 22-39), onde não só as empresas de divulgação midiática são responsáveis pela produção de informações, mas sim todas as pessoas que participam de tal mídia, de tal rede social, que no nosso caso, é o Facebook.

A participação das pessoas que não necessariamente faz parte da organização da página, mas as que concordam ou confrontam para com as suas opiniões, argumentam, compartilham das mesmas ideias e disseminam a informação (ou discordam e fazem o contrário), será tido como objeto de pesquisa para uma melhor compreensão dos pensamentos políticos da população brasileira que se manifesta virtualmente, já que as novas mídias $\mathrm{e}$ as redes sociais integram a vida de muitos brasileiros. Metodologicamente veremos o espaço virtual como espaço de relações sociais, e pretendemos analisar como essas relações influenciam na participação política dos brasileiros virtualmente, remetendo a interpretações sobre o passado, noções de futuro, entre outros.

\section{CONSIDERAÇÕES FINAIS DESTE TEXTO, MAS INICIAIS DESTA PESQUISA}

Consideramos que o objetivo de estudar essa comunidade online abrange várias discussões, entre elas: aliviar o presente de seu autismo, dando foco à história do tempo presente, ao contexto histórico e ao cenário político contemporâneo do Brasil. É necessária uma discussão mais profunda sobre os métodos para se pesquisar esse gigante acervo que é o universo digital. Não damos a solução aqui, mas nos aventuramos a pensá-lo, e a abordá-lo para o estudo das manifestações contra o governo federal brasileiro.

Um universo que cresce a cada momento, onde mais pessoas tem acesso ao mundo virtual, não nos resta alternativa senão pensá-lo como lugar de discussões políticas cotidianas, lugar de buscas de informação, mas também produção e difusão dessas. É por isso que buscar compreender os discursos políticos das postagens da página, não ignorando os comentários, curtidas e compartilhamentos, que demonstram o grau de aceitação e concordância, ou discordância, das ideias veiculadas pela página, se mostrou como um dos objetivos principais da nossa empreitada. O historiador do tempo presente possui um acervo enorme no ciberespaço para se mergulhar. E sem o objetivo de tomar partido nessa pesquisa, pretendemos realizar um estudo sobre essa "direita" do senso comum, do cotidiano, que ganha espaço e afinidade em algumas parcelas da sociedade brasileira.

\section{REFERÊNCIAS}

AIRES, Luísa; AZEVEDO, José. Contributos teórico-metodológicos para a análise de comunidades virtuais de aprendizagem. In: PASSARELLI, Brasilina; AZEVEDO, José. 


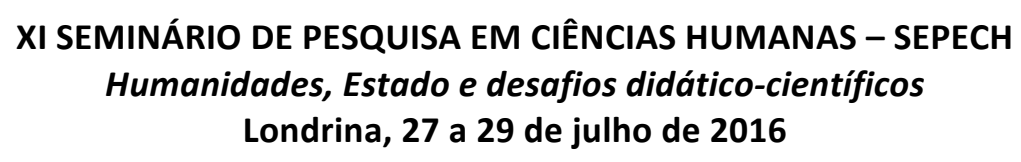

(Orgs.). Atores em rede: Olhares luso-brasileiros. São Paulo: Editora SENAC, 2010. p. 29-61.

COUTO JUNIOR, Dalton Ribeiro do. Cibercultura, Juventude e Alteridade: aprendendo-ensinando com o outro no Facebook. Jundiaí, Paco Editorial: 2013.

HOBSBAWM, Eric. Sobre História. - São Paulo : Companhia das Letras, 2013.

KOZINETS, Robert V. Netnografia. Realizando pesquisa etnográfica online. Porto Alegro: Penso, 2014.

LEFEVRE, Fernando; LEFEVRE, Ana Maria. Pesquisa e representação social. Um enfoque qualitativo. Brasília: Liber Livro Editora, 2012.

LEMOS, André. Os sentidos da tecnologia: cibercultura e ciberdemocracia. In: LEMOS, André; LÉVY, Pierre. O futuro da internet: em direção a uma ciberdemocracia planetária. São Paulo: Paulus, 2010, p. 21-31.

LÉVY, Pierre. As tecnologias da inteligência. O futuro do pensamento na era da informática. Trad. Carlos Irineu da Costa. Rio de Janeiro: Ed. 34, 1993.

Cibercultura. Trad. Carlos Irineu da Costa. São Paulo: Ed. 34, 1999.

LUCCHESI, Anita. Conversas na antessala da academia: o presente, a oralidade e a história pública digital. História Oral, v. 17, n. 1, p. 39-69, jan./jun. 2014.

PISANI, Francis; PIOTET, Dominique. Como a web transforma o mundo. A alquimia das multidões. Trad. Gian Bruno Grosso. São Paulo: Editora SENAC, 2010.

RAMOS, Márcia Elisa Teté. O estudante de Ensino Médio nas comunidades virtuais "eu amo história" e "eu odeio história" e uma questão antiga: para quê serve a história?. Antíteses, v. 5, n. 10, p. 665-689, jul./dez. 2012.

PASSARELLI, Brasilina. Literacias emergentes nas redes sociais: estado da arte e pesquisa qualitativa no observatório da cultura digital. In: ; AZEVEDO, José (Orgs.). Atores em rede: Olhares luso-brasileiros. São Paulo: Editora SENAC, 2010. p. 63-78. 